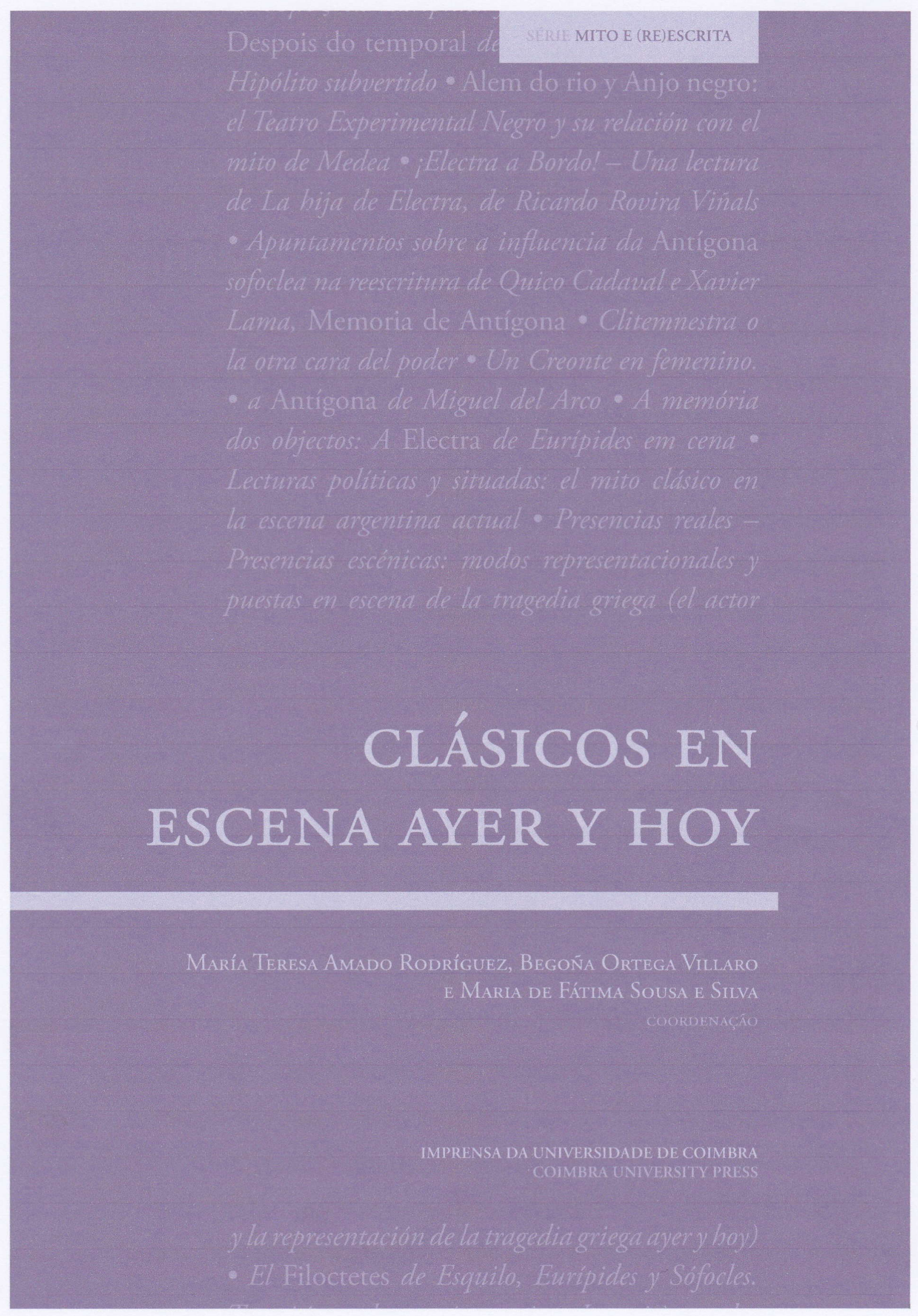


TODOS OS VOLUMES DESTA SÉRIE SÁO SUJEITOS A ARBITRAGEM CIENTÍFTCA INDEPENDENTE.

Título - Clástcos en Escena Ayer y Hoy

Coordenaçáo - María Teresa Amado Rodríguez, Begońa Ortega Villaro,

Maria de Fátima Sousa e Silva

SÉrIe MitTo e (Re)Escrita

Coordenador Científico do plano de edição: Maria do Céu Fialho

Conselho Editoriat

José Ribeiro Ferreira Francisco de Oliveira

Maria de Fátima Silva Nair Castro Soares

Director Técnico: Delfím Leão

OBRA REALIZADA NO ÂMBrTO DAS ACTIVIDADES DA UI\&D

Centro de Estudos Clássicos e Humanísticos

EDIÇĀO

Imprensa da Universidade de Coimbra

URL: http://www.uc.pt/imprensa_uc

E-mail: imprensauc@ci.uc.pt

Vendas online:

http://livrariadaimprensa.uc.pt

COORDENACÁO EDITORIAL

Imprensa da Universidade de Coimbra

CONCEPCÁO GRÁFICA

Carlos Costa

PRE- IMIPRESSÁO

Jorge Neves
Impressáo e Acabamento

Simóes e Linhares, Lda.

ISBN

978-989-26-1836-4

ISBN DIGITAL

978-989-26-1837-1

$\mathrm{DOI}$

https://doi.org/10.14195/978-989-26-1837-1

DepósITo LEgAi.

$465654 / 19$

1. EDIÇAo: IUC/CECH・2019

AMADO RODRÍGUEZ, María Teresa, e outros

Clásicos en escena ayer y hoy / María Teresa Amado Rodriguez, María Begońa Ortega Villaro, Maria de

Fátima de Sousa e Silva. - (Classica digitalia. Mito e (re)escrita)

ISBN 978-989-26-1836-4 (ed. impressa)

ISBN 978-989-26-1837-1 (ed. eletrónica)

I - ORTEGA VILLARO, María Begońa

II - SILVA, Maria de Fátima de Sousa e, 1950

CDU 821.14'02-2.09

(c) Dezembro 2019 .

IMPRENSA DA UNIVERSIDADE DE COIMBRA

Classica Digitalia Vniversitatis Conimbrigensis (http://classicadigitalia.uc.pt)

Centro de Estudos Ciássicos e Humanísticos da Universidade de Coimbra

Reservados todos os direitos. Nos termos legais fica expressamente proibida a reproduçáo total ou parcial por qualquer meio, em papel ou em ediçâo electrónica, sem autorizaçâo expressa dos titulares dos direitos. É desde já excepcionada a utilização em circuitos académicos fechados para apoio a leccionaçáo ou extensáo cultural por via de e-learning. 


\title{
CLÁSICOS EN
}

\section{ESCENA AYER Y HOY}

\author{
María Teresa Amado Rodríguez, Begoña Ortega Villaro \\ e Maria de Fátima Sousa e Silva \\ COORDENAÇÁO
}




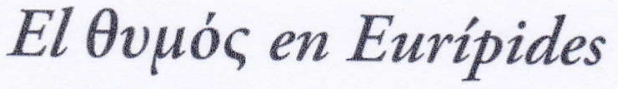 y la peripecia trágica \\ The Ovuós in Euripides \\ and the tragic episode}

Ana Alexandra Alves de Sousa

Universidad de Lisboa

sousal@campus.ul.pt

ORCID: 0000-0001-6515-1668 
Resumen - El Oujós es un término que proviene de los poemas homéricos, en los cuales caracteriza al héroe. En el teatro de Eurípides lo vemos asociado al cambio de suerte trágico. El término se encuentra en once obras de Eurípides: Medea, Heraclidas, Hipólito, Hécuba, Suplicantes, Heracles, Electra, Ifigenia entre los Tauros, Fenicias, Ifigenia en Aulide y Bacantes.

En la tragedia Medea el concepto está en el origen del terrible y tan controvertido infanticidio. Nuestro análisis asocia el término a la esencia del Yo, a su raciocinio y al ímpetu que cambia el trágico destino de personajes como Jasón, Hipólito, Eteocles, Hécuba y Penteo. La inquietante polisemia de la palabra nos llevará así al amor y al

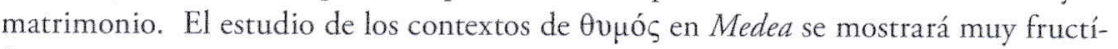
fero porque, en esta tragedia, encontramos toda la complejidad del concepto que las restantes obras dramáticas de Eurípides comprueban. En verdad, el poeta empleó una palabra épica y la travistió con ropajes trágicos.

Palabras clave - $\theta 0 \mu o ́ \varsigma, ~ \pi \varepsilon p \imath \tau \alpha ́ \theta \varepsilon \imath \alpha$, ánimo, entendimiento, ímpetu.

Aвstrat: The $\theta u \mu$ ó $\zeta$ is a concept that comes from the Homeric poems, in which it characterizes the hero. In Euripides' tragedies we see it associated with the change of tragic fate $(\pi \varepsilon \rho \imath \pi \dot{\alpha} \theta \varepsilon ı \alpha)$. The word is found in eleven plays: Medea, Heraclidae, Hippolytus, Hecuba, Supplicants, Heracles, Electra, Iphigenia among the Tauros, Phoenicians, Iphigenia in Aulis and Bacchae.

In the tragedy Medea the concept is connected with the controversial infanticide. Our analysis associates the word with the essence of the Self, with its reasoning and with the impetus that changes the tragic destiny of characters like Jason, Hippolytus, Eteocles, Hecuba and Pentheus. The disturbing polysemy of the word will also lead us to love and marriage. The study of the contexts of $\theta 0 \mu$ ó $\varsigma$ in Medea will be very fruitful because, in this tragedy, we find all the complexity of the concept that the other dramatic works of Euripides prove. In truth, the poet used an epic word and wore it in tragic clothes.

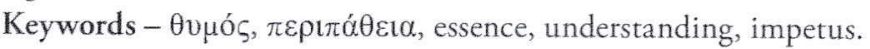

Queremos con este estudio ver cuál es la mejor forma de entender, en el teatro de Eurípides, un término que es muy complejo y de dificilísima traducción, en los textos griegos: $\theta v \mu$ óc. En los poemas homéricos, el $\theta v \mu$ ó aparece como el órgano de control de la angustia; es él quien detiene el dolor si uno se apesadumbra a causa de la pérdida de un hijo o de un hermano (Il.24.49). Sin embargo, puede dar consejos al héroe impeliéndolo a actuar sin beneficio propio: Ulises plantea la duda a Dolón de si había sido su $\theta v$ uós lo que lo había arrastrado al campamento de los aqueos, cuando él y Diomedes lo sorprenden en su misión nocturna y lo matan (Il.10.389). Así, el $\theta 0 \mu o ́ c$ es una fuerza interior que conduce a una acción que puede estar mezclada con un sentimiento de rabia, por eso el término es tan a 
menudo confundido con la rabia ${ }^{1}$. Ulises, después de huir de la gruta del Cíclope, sigue provocándolo, a pesar de las súplicas de sus compañeros, y pone de manifiesto, al narrar la historia, que aquellos no habían alcanzado la persuasión de su magnánimo $\theta v \mu o ́ \varsigma(O d .10 .500)$. Pero el $\theta v \mu o ́ c ̧$ no es siempre activo: Aquiles encanta su Ovuós cuando toca la lira (Il.9.189) y avisa a Agamenón que él iba a despedazarse en el $\theta v \mu o ́ \varsigma$ con su decisión de

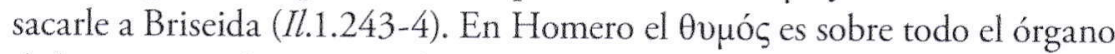
de la sensación, buena o mala (Barnouw 2004: 150): Ulises habla del miedo que Dolón puede estar sintiendo cuando lo coge (Il.10.383). Además, a veces, el $\theta v \mu o ́ s$ no es más que el lugar del pensamiento del héroe homérico: Telémaco dice a su madre que, a consecuencia de su madurez, sopesa en su $\theta v \mu o ́ s$, ya sea los asuntos malos, ya sea los buenos (Od.18.298). Vemos que, a pesar de que se aloja en el interior del Yo, invisible a cualquiera, no coincide exactamente con el Yo, o sea, el héroe lo siente como una parte de sí; es algo que lo constituye ${ }^{2}$. Su asociación al deseo de combatir en el texto homérico (e.g. Il.5.135; 7.2, 74; 9.702) convierte la palabra en sinónimo de "coraje" en la lírica (e.g. Tyrt. fr.10, v.13; fr.12, v.44, West). Sin embargo, en los poemas de Safo aparece como siendo ya el "Yo" (fr.1, v.4 e 27; fr.5, v.3; fr.42, v.1; fr.60, v.6; fr.86, v.5 Lobel \& Page), enamorado y atormentado en el presente (Mas 2003: 45). Incluso en Arquíloco el vocativo $\theta v \mu \varepsilon \dot{\varepsilon}, \theta v ́ \mu^{\prime}$ (fr.128 West) también nos parece que es el Yo que mantiene un diálogo consigo mismo (Mastronarde 2002: 339). Recco (2007: 54) defiende que

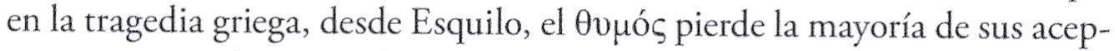
ciones, surgiendo casi exclusivamente como "rabia" y "coraje". Sin embargo, propondremos otras hipótesis para entenderlo en la tragedia euripidea a través del análisis de los contextos en los cuales aparece la palabra. Once dramas de Eurípides la contienen, sobresaliendo Medea donde surge nueve veces, mientras que en los otros diez dramas lo encontramos como máximo dos veces.

Nuestro estudio tendrá dos partes. En la primera, veremos cómo el $\theta v \mu o ́ s$ se identifica con la personalidad y la comprensión que los caracteres

${ }^{1}$ Crane (1987: 172) defiende que esa es la acepción más frecuente del concepto homérico. No queremos exponer aquí toda la controversia que el uso del término en los poemas homéricos ha desencadenado, sino subrayar las múltiples posibilidades de entenderlo.

2 Por eso Mas (2003: 45), como otros estudiosos, lo entiende como "una fuerza externa al mismo sujeto, algo que se impone desde afuera”. Chantraine (1999: 446) lo ve en los poemas homéricos como "siège des sentiments et notamment de la colère" y por eso "ardeur, courage". 
hacen de las situaciones, es él quien define el Yo, su ser y su juicio. En la

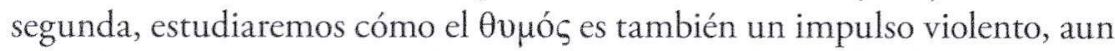
animalesco, que se enajena del carácter practicando crueldades que ponen en duda la virtud del Yo y que càmbian la fortuna trágica de los personajes.

\section{1. @vpós: estado de espíritu que define el Yo en su carácter y entendimiento}

Como trazo definidor del carácter, el $\theta 0 \mu o ́ s$, con tal de que esté incólume, es positivo y deseable, como también lo es la fortuna con prosperidad.

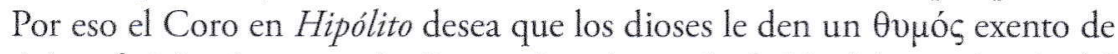
dolores $^{3}$ : Menelao, cuando Orestes le pide ayuda, habla del gran $\theta 0 \mu o ́ \varsigma$ del pueblo como "un bien precioso para quien espera". Aquiles promete ayuda a Clitemestra con respecto a la salvación de Ifigenia, hablándole del magnánimo $\theta v \mu$ ó cual se crispaba con la idea del sacrificio de la muchachas.

Además de la asociación del concepto a la prosperidad, a la compasión

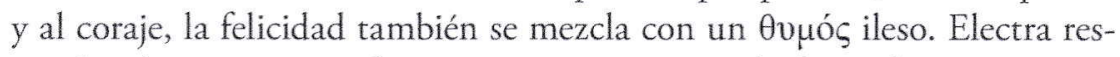
ponde a las argivas que la invitan a participar en la fiesta de Hera que no sentía "disposición anímica para festividades, ni tampoco para adornarse con collares de oro"

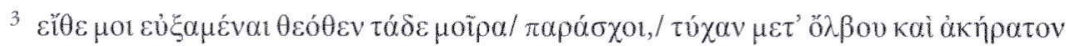

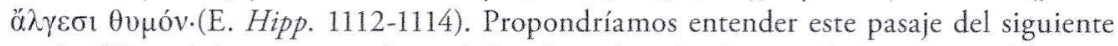
modo: "Que el destino procedente de los dioses/me dé, después de mis ruegos,/ fortuna con prosperidad y un ánimo exento de dolores".

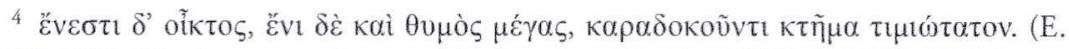

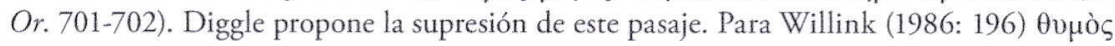

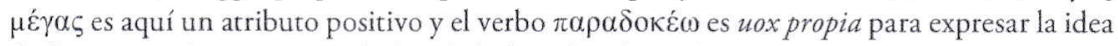
de "wainting the outcome of a battle before deciding which side to join". Nos parece que "gran ánimo" traduciría bien la expresión.

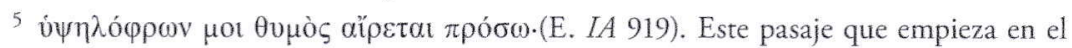
verso 919 ha sido muy golpeado por los filólogos: para Page estos versos, hasta el 1035, son posteuripideos y evidencian la técnica de la comedia nueva; England solo reconoce como auténticos veintitrés de cincuenta y cinco versos; Ritchie, en cambio, concluye por la coherencia y autenticidad del pasaje, opción que es también la de Jouan en su edición (1983: 141). Sobre su traducción cf. n. 19.

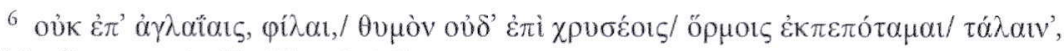

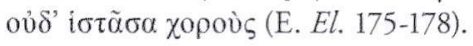


En dos de estos pasajes el cambio de fortuna ocurre o se desea: Orestes quiere salvarse y lo logrará; Clitemestra busca la salvación de su hija, pero no la alcanzará. En los otros dos pasajes no se plantea la cuestión de cambio de fortuna: en el primero, el Coro está haciendo una plegaria para ser feliz y, en el último, Electra rechaza la felicidad. Por supuesto que a Electra le gustaría una vida afortunada y digna de su condición social, pero Clitemestra la había herido fuertemente.

Este $\theta v \mu o ́ s$, que es generoso, compasivo, valiente y festivo, es también presentimiento y raciocinio, porque tiene aptitud para comprender y evaluar las situaciones. En Alcestis, Heracles explica que había entrado en casa de Admetus y había empezado a divertirse "en contra de su estado de espíritu"7. El personaje, que va a rescatar a Alcestis del reino de los muertos, luchando contra el dios Muerte, presintió el infortunio del rey, cuando traspuso la puerta de su casa. Por eso, describe como una violencia contra su

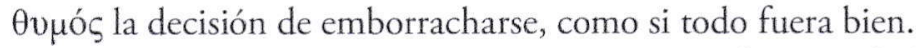

Del mismo modo el Ovuós de Peleo, en Andrómaca, lo hace intuir el anuncio de la muerte de su nieto Neoptólemo, antes de que se lo cuenten ${ }^{8}$. A pesar de que el $\theta v \mu o ́ c ̧$ recibe aquí el calificativo de profético, no diríamos que tuviera una aptitud para la adivinación, sino que es el propio raciocinio o entendimiento que alguien hace sobre una situación con la cual está teniendo contacto. La explicación que el Corifeo hace a Peleo sobre la inminencia de la muerte de Neoptólemo, su nieto, lleva a Peleo, viendo al Mensajero, a prever que Orestes ya lo había asesinado?

También la aceptación, por parte de Electra, de los signos de reconocimiento deriva del raciocinio de la muchacha, aunque ha sido desencadenado por el Anciano. Este había llamado su atención sobre la cicatriz junto a la ceja de Orestes delante de ella, recordándole el incidente de la persecución

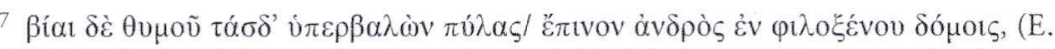
Alc. 82-309). Parker (2007: 215) subraya la agresividad da la expresión que entiende más fuerte que "en contra" y para la cual propone la traducción "doing violence to my feelings".

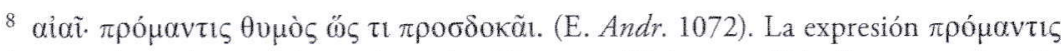
$\theta v \mu o ̀ s$, para la cual sugeriríamos la traducción como "ánimo profético", evoca a Esquilo (A. P. 10-11), como subraya Lloyd (2005: 166).

9 No coincidimos así con la explicación de Lloyd (2005: 166), que cita a Peliccia para concluir que, en este pasaje, tenemos el $\theta v \mu o ́ s$ actuando de modo racionalmente inexplicable. 
de una cervatilla, en el cual los dos hermanos habían participado. El Өvjós de Electra se deja persuadir entonces; ella lo declara ${ }^{10}$.

Para Medea es también producto de un juicio hecho por el $\theta 0 \mu o ́ \varsigma$ del rey la decisión de elegir a Jasón como su yerno ${ }^{11}$. En este pasaje tenemos la protagonista explicando el cambio de fortuna a partir del $\theta v \mu o ́ c ̧$ de un tercero. En los pasajes anteriores son los propios personajes quienes asocian su $\theta v \mu o ́ \varsigma$ a la mudanza presentida: el $\theta v \mu o ́ s$ de Heracles, después de confirmar

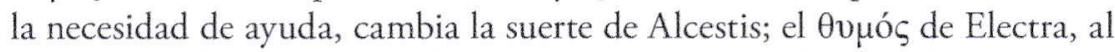
persuadirse de que estaba delante de Orestes, cambia la desdicha de la protagonista, trayéndole la felicidad de saber que serían vengados los crímenes

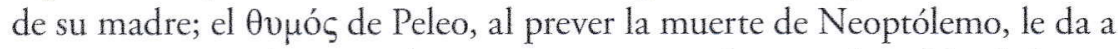
conocer anticipadamente el acontecimiento que le traerá la infelicidad.

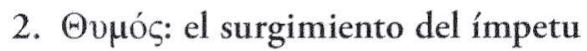

Este $\theta 0 \mu o ́ \varsigma$ que define a la persona en su esencia e inteligencia es también el ímpetu inherente a la práctica de actos dañinos o el furor que resulta de estos. ¿Qué sucede para que la esencia de uno, o sea el $\theta 0 \mu o ́ s$ número uno, se convierta en ímpetu, el $\theta v \mu$ óc número dos?

En primer lugar, este ímpetu es una consecuencia de un daño hecho al $\theta v \mu o ́ c$, entendido como Yo. La fuerza de un $\theta v \mu o ́ \varsigma$ herido es muy grande y desdichada. El Coro de las mujeres de Corinto, en Medea, habla del ímpetu creciente de la infelicidad, que en los versos es representada por la imagen de una nube de gemidos ${ }^{12}$.

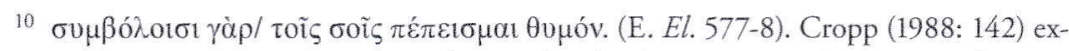
plica sintácticamente este pasaje diciendo que el verbo tiene un acusativo griego, tal como, añadiríamos, el verso 8 en $M e d e a$, comentado, del punto de vista semántico, por nosotros en la nota 31. Propondríamos para entenderlo algo como "mi ánimo está persuadido/con tus señales".

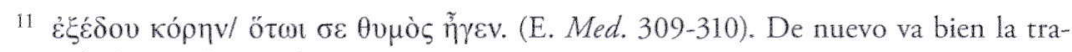
ducción de "ánimo" para el término $\theta 0 \mu o ́ s$.

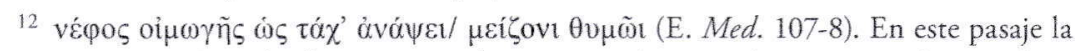

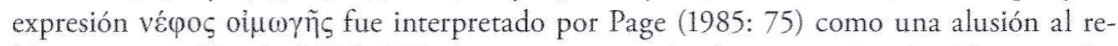
lámpago y por Diggle (1994: 278) al trueno que, según algunas teorías científicas, resulta del efecto del fuego en una nube. Mastronarde (2002: 183) duda de la lectura de Diggle y prefiere entendenlo como una imagen que resulta de la preocupación de la Nodriza, ya sea con "the climatic boom", ya sea con "the destructive flash", o sea, diríamos nosotros con la fuerza deletérea del ímpetu $(\theta v \mu o ́ \varsigma)$ de Medea, que iba a herir a alguien. 
Cuando este Coro dice que desea nunca ser herido por Cipris, está explicando una de las causas para el surgimiento de este ímpetu ${ }^{13}$ : el amor. Por eso será fatal que Medea tenga su $\theta v \mu o ́ c ̧$ herido en el amor a Jasón, como dice la Nodriza describiendo a su señora, al inicio del drama ${ }^{14}$. La promesa

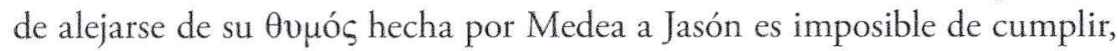
así que ella la hace con una interrogativa negativa, que deja entrever la naturaleza dolosa de este propósito ${ }^{15}$.

El amor que hiere el $\theta u \mu o ́ c ̧$ resulta, por lo tanto, de una ruptura de la fidelidad y del respeto. Cuando Hipólito dice a su padre que lo expulse del país si ese es su $\theta v \mu o ́ \varsigma^{16}$, está refiriéndose a un $\theta v \mu o ́ \varsigma$ que había sido herido con la idea de que Hipólito había violado a Fedra. Son los celos los que llevan al rey a dirigir maldiciones a Posidón. Su $\theta$ upós había sido destrozado por las palabras que Fedra, su mujer, había escrito en una tablilla, acusando a su hijastro de seducción. Para Hipólito de esta forma queda claro que su destierro es un castigo que adviene de la herida del $\theta v \mu o ́ s$ de Teseo, que pronto creyó en la declaración de su mujer.

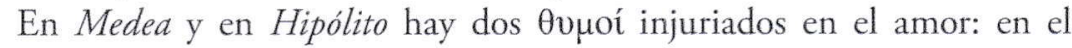
primer drama, el $\theta v \mu o ́ c ̧$ de Creonte, en la acepción de "entendimiento", desencadena el $\theta v \mu o ́ s$ de Medea, en la acepción de "ímpetu", los cuales producen el cambio de fortuna; en el segundo drama, el $\theta u \mu o ́ \varsigma$ de Teseo, en la acepción de "ímpetu", desencadena el cambio, como resultado del $\theta v \mu$ ó de Cipris. Teseo comprende que había sido un instrumento de la diosa, cuando Artemis le dice, después de todas las muertes, que todo había sido una venganza de Cipris. De hecho, esta diosa sentía su $\theta u \mu o ́ c ̧$ injuriado por la impiedad de Hipólito, que no la reverenciaba. Artemis consuela a Teseo, revelándole que la diosa satisfizo su ímpetu ${ }^{17}$.

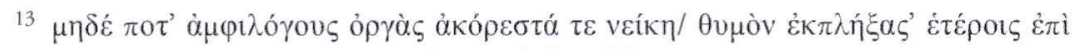

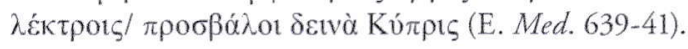

14 Ěp cf. n. 10 .

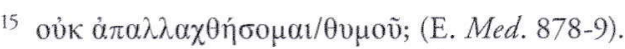

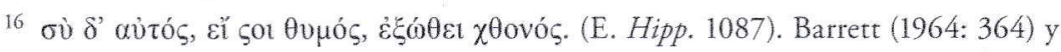
Halleran (1995: 123) traducen $\theta 0 \mu o ́ c$ como "desire", nosotros, en el contexto, preferiríamos "ímpetu".

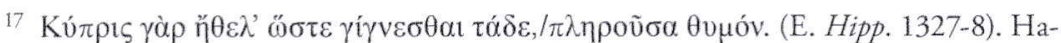
lleran (1995: 135) opta otra vez por la traducción "desire" y Barrett (1964: 401) habla de "passions or desires". Nosotros mantendríamos la solución ya propuesta en la nota anterior. 


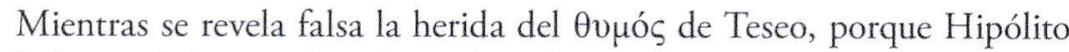
no había violado a Fedra, el rey descubre que había sido un instrumento del verdadero $\theta 0 \mu$ ó $̧$ herido: el de Cipris. En este caso el hombre que es Hipólito había roto la fidelidad y el respeto debidos, no a alguien concreto, sino al propio amor. Resulta así fatal para los mortales no valorar el amor y el compromiso que se le asocia. Las muertes en Medea e Hipólito lo comprueban.

Otras fuerzas, además del amor, pueden romper el $\theta v \mu o ́ c$. Teseo en un enunciado proverbial, en Suplicantes, recuerda que los que son injuriados moderadamente deben soportarlo sin ímpetu ${ }^{18}$. Las injurias, $\dot{\alpha} \delta$ tкíat, en general hieren el $\theta u \mu o ́ c$. Esta podría ser la situación de Aquiles, en Ifigenia en Aulide, al descubrir que estaban sirviéndose de su nombre como novio en una boda que solo era una artimaña para atraer a Ifigenia y sacrificarla. Por eso el Anciano pregunta a Agamenón si no temía que aquel se molestara con

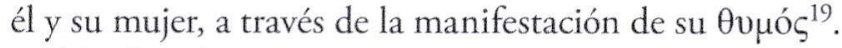

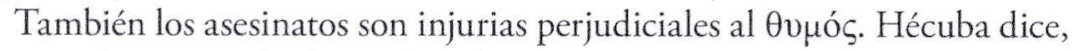
después de matar a los hijos de Poliméstor, que era tiempo de marcharse y

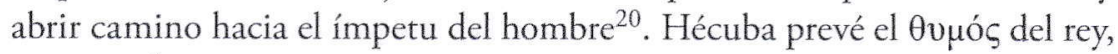
porque sabía que su venganza causaría el mismo daño que el rey ya le había causado, matando a su hijo.

Cuando alguien, aun injuriado, escucha y satisface las demandas que recibe para detener su ímpetu, el cambio trágico no tiene lugar. Así, después del reconocimiento de los hermanos, Orestes e Ifigenia, cuando la diosa ex machina ordena al rey de los Tauros que se aleje de su ímpetu, ya no se

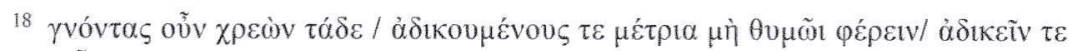

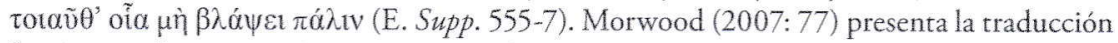
"with anger" para $\theta 0 \mu \tilde{\omega}$ t, pero mantendríamos nuestra propuesta anterior de "ímpetu": "que los moderadamente injuriados lo soporten sin ímpetu/y que no cometan injusticias que volverán a dañar a todos”.

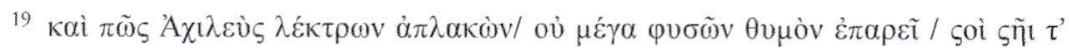

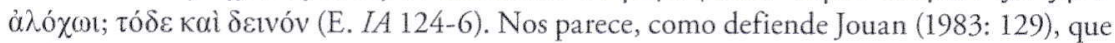
no hay manifestación de estulticia por parte del Anciano, sino que este está viendo muy claramente lo que iba a pasar, en cuanto el héroe se diera cuenta de que él había sido un medio para cumplir otros fines. Stockert (1992: 213) entiende "den $\theta 0 \mu \hat{́} \varsigma$ erheben" como "in Wut geraten. Sin embargo, nosotros volveríamos a la traducción de ímpetu. Propondríamos algo como: "¿Y cómo Aquiles, privado del lecho nupcial,/ no alzará su gran ímpetu, resoplándolo,/ contra ti y tu esposa?”. La imagen del $\theta 0 \mu o ́ \varsigma$ que se alza remite al verso 919

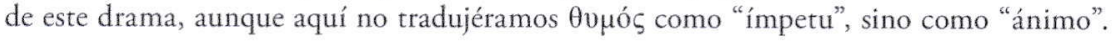

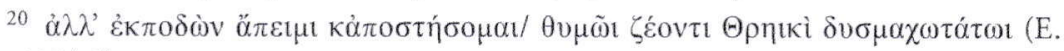
Hec. 1054-5). 
producen más cambios, porque la peripecia trágica había llegado a su fin ${ }^{21}$. Tampoco los hay a causa de la hija de Creonte, cuyo ímpetu siente Jasón. Según el Mensajero, Jasón había pedido a su novia que cediera a su $\theta v \mu o ́ s$ y que no despreciara a quien era su amigo ${ }^{22}$. La princesa le obedece, siendo acogedora con los hijos de Jasón, a quienes recibe en su casa. Será el $\theta 0 \mu o ́ s$ de Medea el que seguirá conduciendo la peripecia trágica. Toante y la hija de Creonte tal vez estén en la situación de los templadamente injuriados, apuntados por Teseo, mientras que Aquiles no sufre siquiera la injuria, al contrario de Hécuba.

Además de las injurias, hay otro impulso que arrastra a los hombres, burlándolos, y que los lleva a un exceso que resulta fatal. De nuevo en Suplicantes nos topamos con la explicación para esta fuerza. El Heraldo, que aconseja al rey Teseo que obedezca a las pretensiones de Creonte, le pide que, antes de contestarle, se acuerde de que fue la esperanza la que contrapuso a muchas ciudades llevando su ímpetu a un exceso que siempre termina en la guerra ${ }^{23}$. Así sucede a Eteocles, en Fenicias. Por eso su madre, Yocasta, le demanda que contenga su "ímpetu violento", pensando que un diálogo con Polinices podría originar un retroceso en su posición ${ }^{24}$. Vano es el discurso, porque el exceso ya dominaba a Eteocles y de ello resultará la muerte de los dos hermanos ante de las puertas de la ciudad. También Euristeo se deja llevar por el exceso al sentirse por encima de la justicia. La persecución que mueve a todos los descendientes de Heracles es la expresión

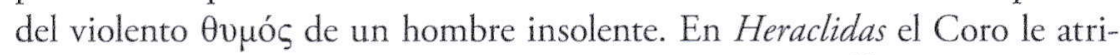
buye "un ímpetu violento, prevaleciente sobre la justicia"25.

En estos dos pasajes, el análisis es hecho siempre por alguien que quería ver el conflicto resuelto: la madre que amaba a sus hijos y los ciudadanos de Atenas, para quienes era natural respetar a los suplicantes. Quienes sufren el cambio trágico de fortuna, Eteocles y Euristeo, no perciben que estaban

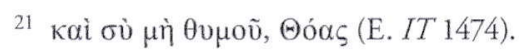

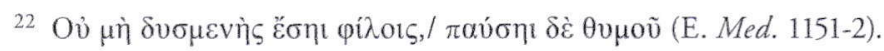

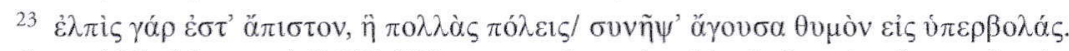
(E. Supp. 480). Morwood (2007: 77) presenta la traducción de "passions" para $\theta 0 \mu o ́ s$, nosotros mantendríamos "ímpetu".

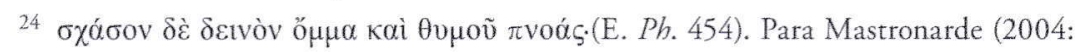
278) $\theta 0 \mu 0 \tilde{~} \pi$ voás es una manifestación de locura o de cólera, que el estudioso traduce por "agitated breathing"; preferiríamos una opción más literal, algo como "los resoplidos de tu impetu".

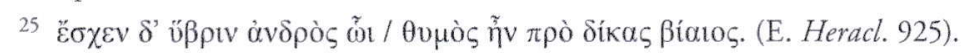


teniendo un ímpetu violento e insolente, al contrario de lo que le ocurre a Medea, que siente la fuerza de su ímpetu, y a Hipólito, que siente el ímpetu paterno. Por eso no se plantea la cuestión de saber si, en estos casos, el $\theta 0 \mu o ́ \varsigma$ se asocia a la responsabilidad. Si el punto de vista es ajeno y quien sufre el revés no reconoce que hay un ímpetu letal actuando, no tiene sentido hablar de la conciencia del Yo actuante.

Tampoco se plantea el problema de la responsabilidad cuando el $\theta v \mu o ́ s$ es alejado de la conciencia, por acción de los dioses, o sea, cuando los hombres actúan sin saber lo que están haciendo. Hera castiga a Heracles a través de Iris y Lisa, personificación de la demencia o del furor, a las cuales envía para que lo empujen a asesinar a su familia, mujer e hijos. Anfitrión habla

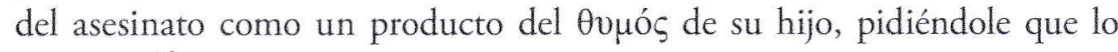
contenga ${ }^{26}$.

Anfitrión realza la pujanza homérica de este $\theta 0 \mu$ ós, asociándole un ímpetu de león ${ }^{27}$. Como en el caso de Hipólito, este ímpetu adviene del de un dios: el de Hera que había sido herido por los amores de Zeus y Alcmena, de los cuales había resultado el nacimiento del héroe. Sin embargo, sobre eso no se dice nada, sino que la diosa esperaba, para poner en práctica su venganza, el fin de los trabajos que Euristeo impuso a Heracles cuando Zeus lo protegía. Mientras que Hipólito siente el ímpetu de su padre y reconoce el cambio que va a suceder (no siente el de Cipris, que ignora), Heracles, el personaje que sufre el cambio de fortuna, no sabe que está cometiendo una atrocidad, porque Hera le quita la conciencia. Anfitrión señala el ímpetu de su hijo, porque lo siente, lo comprueba, al ver a los nietos muertos.

Algo semejante al procedimiento de Hera es lo que Dioniso hace a Penteo, rey de Tebas. En respuesta al ultraje que había recibido, cuando su culto había sido prohibido en Tebas, el dios confundió a Penteo, haciéndolo atrapar un toro, persuadido de que estaba cogiendo a Dioniso. Este

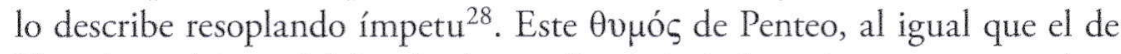
Heracles, adviene del $\theta v \mu o ́ \varsigma$ de un dios injuriado y tiene una naturaleza animalesca por pertenecer a alguien que exhibe más fuerza que un toro.

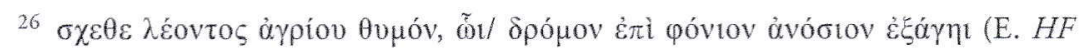
1211-2).

27 Conviene que recordemos que los poemas homéricos también hablan del $\theta 0 \mu$ ó los animales (e.g. Il. 3.394; 12.150).

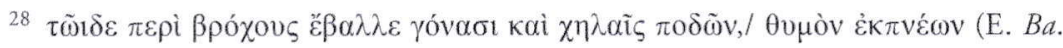
619-20). El modelo sigue siendo homérico (Dodds 1960: 154). 
Mientras que las injurias a los dioses desencadenan el ímpetu de los mortales, sin que estos lo sepan (Teseo, Heracles, Penteo) y la ambición insolente está clara solo para quien observa la conducta de los que se alzan (Eteocles, Euristeo), las injurias sentidas por los hombres desencadenan el $\theta v \mu o ́ s$ con perfecta conciencia de quien las sufre (Hipólito, Medea) o de quien las provoca (Hécuba y los dioses).

Siendo este furor expresado con el término que señala la esencia de la persona, el Yo, se plantea la cuestión de saber cómo Eurípides ve la responsabilidad de quien, sintiendo la fuerza negativa del ímpetu, actúa perjudicialmente. El trágico evita el problema en casi todos los dramas, ya sea quitando la conciencia a los personajes (Heracles, Penteo, Teseo), ya sea atribuyéndoles una ambición insolente, imperceptible para él mismo (Eteocles, Euristeo).

¿Pero cómo analizar los caracteres de Hécuba y Medea que actúan sabiendo que habían realizado o iban a realizar una barbaridad? En los dos casos tenemos la muerte de hijos; la gran diferencia es que Hécuba no mata a sus hijos, sino a los de Poliméstor.

Hécuba, al prever el furor del rey tracio cuando descubra que asesinaron a sus hijos, prueba que había sentido su $\theta 0 \mu o ́ \varsigma$ cuando el rey mató a Polidoro, su hijo. Hubo una primera herida, que resulta del asesinato de Polidoro. De esta herida advino un furor, que condujo a Hécuba a matar a los dos hijos de aquel rey, cuyo ímpetu sería desencadenado por las nuevas muertes. Hay una transferencia de $\theta 0 \mu$ oí: del de Hécuba al de Poliméstor. La imposibilidad de perpetrar una atrocidad equivalente, que apaciguara el $\theta v \mu o ́ \varsigma$ del rey, lo vuelve inextinguible y hace más grande la venganza de Hécuba: ella mata a sus hijos y convierte al rey casi en la personificación del furor. Este es el mayor furor que uno puede sentir, porque no tiene cómo resolverlo.

Medea, al contrario de Hécuba, tiene que matar a sus hijos, después de matar al rey y a su hija, porque para ella son dos las causas de su injuria: la

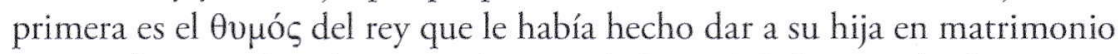
a Jasón; la segunda es la propia decisión de Jasón. Medea resuelve la primera matando al rey y a su hija, sin arrepentimiento, porque todo ocurre fuera del seno familiar; con la segunda, todo es diferente.

Antes de haber asesinado a sus hijos, Medea habla consigo misma y reconoce que su ímpetu es "mayor que sus resoluciones" de no matarlos ${ }^{29}$.

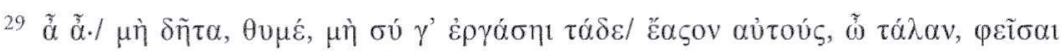

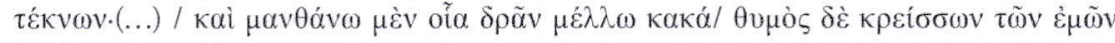

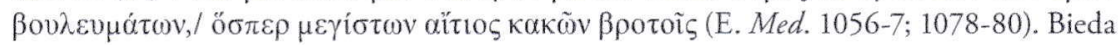


Cuando declara, angustiada, la imposibilidad de refrenar su $\theta$ vuó $\varsigma$, Medea es una víctima de aquel. Anteponiendo el horror al acto, ella admite que este era abominable aun para sí misma. Y cuando el Coro prevé que será imposible conciliar tranquilamente su $\theta v \mu o ́ s$ con las atrocidades cometidas plantea la cuestión de la responsabilidad que Medea va a sentir, en el momento del asesinato ${ }^{30}$.

La cuestión de la responsabilidad de Hécuba es totalmente diferente, porque ella, al saber que inflige, en otra familia, una pérdida equivalente a la suya, no siente arrepentimiento. Sin embargo, para el Coro de las muje-

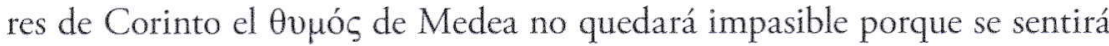

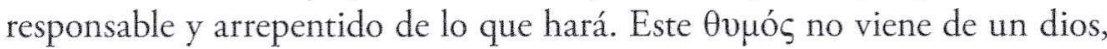
sino que es el de Medea. La protagonista, de hecho, habiendo lamentado ya las muertes de los hijos y habiendo sentido arrepentimiento a causa de ellas, intenta evadirse de su responsabilidad. Sin embargo, quien analiza sus actos, en este caso el Coro - representativo de los hombres que la han juzgado y mirado durante siglos- no la exime e incluso piensa que ella se sentirá responsable. Cuando el Coro dice que ella no quedará impasible mirando a los niños arrodillados, está defendiendo la idea de que Medea se juzgará a sí misma responsable, mientras actúa. Así, en esta tragedia, el concepto de $\theta 0 \mu o ́ s$ permite presentar a la protagonista como víctima y responsable al mismo tiempo. Medea, al reconocer la fuerza incontrolable de su $\theta v \mu o ́ s ~(v .1079)$, como si fuera víctima de él, reclama el lugar del héroe homérico. Pero la protagonista sabe que es consigo misma con quien está hablando cuando se dirige al $\theta v \mu o ́ c(v .1056)^{31}$. En vano busca en los héroes homéricos la justificación para su crimen, viviendo ella en un siglo que se inquieta ya con la búsqueda de la responsabilidad de los hombres.

(2006: 89) subraya la importancia de traducir el término $\beta$ ov $\ell \varepsilon v ́ \mu \alpha \tau$ sin "descuidar aquel matiz que tiene que ver con 'determinar o resolver después de deliberar". Todo este pasaje es suprimido por Diggle en su edición, después de más de un siglo de discrepancias desde Bergk 1884. Mastronarde, que acepta el pasaje (2002: 344-5), interpreta el controvertido verso 1079 como un recurso de Medea para disociarse de su plan de venganza, idea que nos parece inequívoca. Pero nos parece que los $\beta$ oud $\varepsilon v \dot{\mu} \alpha \tau \alpha$ remiten al dolor que su acto va a causarle, lo que es para Mastronarde (2002: 345) "not convincing". Gill (1996: 223) resuelve el problema de otro modo. En su opinión hay complementariedad entre $\theta 0 \mu$ ó $y$

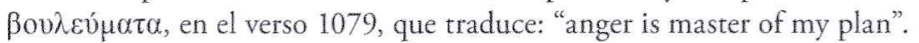

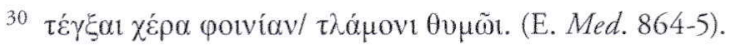

31 Bieda (2006: 90) explica la relación dialéctica entre los dos conceptos, $\theta 0 \mu o ́ \varsigma$ y

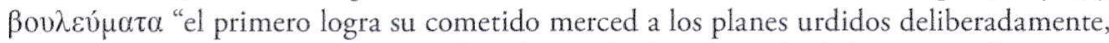
mientras que dichos planes sólo son llevados a cabo bajo la égida de las pasiones". 


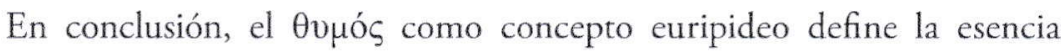
(Aquiles, Electra) y el entendimiento del Yo (Heracles, Peleo, Electra, Creonte) y hasta sus impulsos (Medea, Teseo, Poliméstor, Eteocles, Euristeo, Heracles, Penteo). Estos se desencadenan con tal de que se produzca una herida en los afectos. Cuando el furor despierta y actúa, tenga él un origen divino o humano, hay un perjuicio atroz, que cambia la fortuna de los personajes ( $\pi \varepsilon \rho \imath \tau \alpha \dot{\theta} \varepsilon \iota \alpha)$, haciendo que ocurran muertes en el seno de una familia. Mueren hijos, cónyuges y hermanos: en Hécuba, son asesinados el hijo de la protagonista y los hijos del rey tracio; en Medea, los hijos de la protagonista a sus propias manos, además del rey y su hija; en Hipólito, el protagonista muere; en Heracles, la mujer y los hijos son asesinados por el propio Heracles; en Fenicias, los hermanos Eteocles y Polinices se matan; en Bacantes, la locura de Penteo preludia su muerte, descuartizado por su madre Agave. El Ovuós es, al mismo tiempo, buena predisposición para actuar y buen entendimiento de la situaciones, pero también es fuerza deletérea, como consecuencia de una herida insanable. En este caso se confunde con la rabia y la ausencia de discernimiento, aunque es la esencia de uno y su raciocinio.

\section{Bibliografia}

Barnouw, J. (2004). Odysseus, Hero of Practical Intelligence: Deliberation and Signs in Homer's. Lanham, Maryland: University Press of America.

Barrett, W. S. (1969). Euripides. Hippolytos; edited with introd. and commentary. Oxford: Clarendon Press.

Bergk, T. (1884). Griechische Literaturgeschichte III. Acceso en 14/12/2018, en https://archive.org/details/griechischeliter03berguoft/page/26

Bieda, E. (2006). "Medea, madre enfurecida. Sobre los alcances del thymós en la

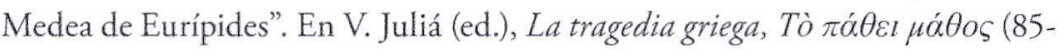
98). Barcelona: Azul editorial.

Chantraine, P. (1999). Dictionnaire étymologique de la langue grecque: histoire des mots. Paris: Klincksieck.

Crane, G. (1987). "The laughter of Aphrodite in Theocritus, Idyl I". Harvard Studies in Classical Philology, 91, 161-184.

Cropp, M. J. (1988). Euripides. Electra, with translation and commentary. Warminster: Aris \& Phillips.

Diggle, J. (1994). Euripidea: Collected Essays. Oxford: Clarendon Press. 
Dodds, E. R. (1966). Euripides. Bacchae: edited with introduction and commentary ( $2^{a}$ ed.). Oxford: Clarendon Press.

Gill, Ch. (1996). Personality in greek epic, tragedy and philopsophy. Oxford: Clarendon Press.

Halleran, M. R. (2004). Euripides. Hippolytus; with introd., translation and commentary (reprinted with corrections). Warminster: Aris \& Phillips.

Jouan, F. (1983). Euripide. Iphigénie à Aulius, texte établi et traduit. Paris: Les Belles Lettres.

Lloyd, M. (2005). Euripides. Andromache, with introd., translation and commentary (2a ed.). Warminster: Aris \& Phillips.

Mas Torres, S. (2003). Ethos y polis: una historia de la filosofia práctica en la Grecia Clásica. Madrid: Istmo.

Mastronarde, D. J. (2002). Euripides. Medea, edition with introd. and commentary. Cambridge: University Press.

Mastronarde, D. J. (2004). Euripides. Phoenissae, edition with introd. and commentary. Cambridge: University Press.

Morwood, J. (2007). Euripides. Suppliant women, with introd., translation and commentary. Warminster: Aris \& Phillips.

Page, D. L. (1985). Euripides. Medea: the text edited with introduction and commentary (10a ed.). Oxford: Clarendon Press.

Parker, (2007). Euripides. Alcestis, with introd. and commentary. Oxford: University Press.

Recco, G. (2007). Athens Victorious: Democracy in Plato's Republic. Plymouth: Lexington Books.

Snell, B. (1967). Scenes from Greek drama. Berkeley: University of California Press. Stockert, W. (1992). Euripides. Iphigenie in Aulis: Detailkommentar. Vol. 2. Wien: Österreichischen Akademie der Wissenschaften.

Willink, C. W. (1986). Euripides. Orestes, with introduction and commentary. Oxford: Clarendon Press. 